\title{
Influencing Patient Adherence to Treatment Guidelines
}

\author{
Susan W. Butterworth, PhD, MS
}

\begin{abstract}
BACKGROUND: As chronic disease continues to weigh more heavily on health care resources, lifestyle management and compliance to treatment become paramount to patient care and care coordination. Although a wealth of information is available to the public regarding the basic tenets on exercise, nutrition, weight management, power of medications, and so forth, patients do not always modify their behavior accordingly to improve their overall health. Motivation seems to be both the key element as well as the central puzzle in efforts to change behavior.
\end{abstract}

OBJECTIVE: To identify several strategies, including motivational interviewing, that can be used to reduce resistance and improve the odds of achieving positive clinical outcomes among noncompliant/resistant patients.

SUMMARY: Providers once thought the following about nonadherent patients: They don't see (are in denial or lack insight), they don't know, they don't know how, and/or they don't care. However, instead of focusing on the reasons why people do not change, researchers in behavior change science recognize that the best questions to ask are: "Why do people change?" and "What can we do to help?"

A worst-case scenario undermining positive clinical outcomes is one in which the provider is arguing for change while the patient argues against it. It is, therefore, more effective to enlist strategies that address the complex interaction of motivations, cues to action, perception of benefits and consequences, expectancies, environmental and cultural influences, self-efficacy, state of readiness to change, ambivalence, and implementation intentions. Motivational interviewing is one such approach that is evidence based and increasingly well proven. Motivational interviewing is a client-centered, goal-oriented method for enhancing intrinsic motivation to change by exploring and resolving ambivalence, and it offers more than simply wellintentioned advice or scare tactics.

CONCLUSION: A client-centered approach is the most important component of a health coaching skill set. Patients can ascertain whether you are truly attempting to understand their situation instead of merely trying to manipulate them into change. Respecting each patient's autonomy, drawing out ambivalence about change, evoking change talk, and allowing the patient to develop and/or own the treatment plan greatly improve the odds of achieving positive clinical outcomes.

J Manag Care Pharm. 2008;14(6)(suppl S-b):S21-S25

Copyright@ 2008, Academy of Managed Care Pharmacy. All rights reserved.

Author

SUSAN W. BUTTERWORTH, PhD, MS, is an Associate Professor and a Director of Health Management Services at Oregon Health and Science University (OHSU), Portland, Oregon. She is also a member of the Motivational Interviewing Network of Trainers.

AUTHOR CORRESPONDENCE: Susan Butterworth, PhD, Associate Professor, Director of Health Management Services, Oregon Health and Science University School of Nursing, 3455 SW US Veterans Hospital Rd., Mail Code: SN-4N, Portland, OR 97219. Tel.: 503.494-0386;

Fax: 503.494-3691; Email: butterwo@ohsu.edu
$\mathrm{Y}$ ou would think that having had a heart attack would be enough to persuade a man to change his diet, exercise more often, and take his medication. You would think that hangovers, damaged relationships, an auto crash, and memory blackouts would be enough to convince a woman to stop drinking. You would think that coughing bouts and severe shortness of breath would dissuade those with chronic obstructive pulmonary disease from smoking or that the very real threats of blindness, amputations, and other complications from diabetes would be enough to motivate weight loss and glycemic control. And yet, it is not enough.

As chronic disease continues to weigh more heavily on health care resources, lifestyle management and compliance to treatment become paramount to patient care and care coordination. We are well acquainted with behaviors and treatment guidelines that prevent and help to manage chronic conditions. The public has access to a wealth of information regarding the basic tenets on exercise, good nutrition, weight management, power of medications, and so forth. The provider has a plethora of materials from which to choose. So why don't people change once they know what they should do, especially in life-threatening situations? Why don't they fill their prescriptions and take their medication as prescribed? Motivation seems to be both the key element, as well as the central puzzle, in efforts to change behavior.

\section{Why Don't People Change?}

Historically, providers believed in 4 popular notions concerning their patients' struggles to adhere to their treatment plans. Providers thought the following about their nonadherent patients: They don't see (are in denial or lack insight), they don't know, they don't know how, and/or they don't care. Operating under these assumptions, it made sense to apply the corresponding common solutions:

- Give them insight: If you can just make people see, then they will change.

- Give them knowledge: If people just know enough, then they will change.

- Give them skills: If you can just teach people how to change, then they will do it.

- Give them a hard time: If you can just make people feel badly or afraid enough, then they will change.

Yet, we know that this, too, is not enough. Researchers in behavior change science recognize that the best questions to ask are: "Why do people change?" and "What can we do to help?"

\section{Why People Change}

Over the last 2 decades, researchers have explained behavior change by exploring the following theories: priorities and values (Values Theory), perceived benefits and consequences (Health Belief Model), self-efficacy (Social Cognitive Theory), 


\section{TABLE 1 Typical "Yeah-But Dance"}

\begin{tabular}{l|l}
\hline Pharmacist: & $\begin{array}{l}\text { "I see that you haven't filled this prescription in quite a } \\
\text { while." }\end{array}$ \\
\hline Patient: & "Yeah, I've just been really busy." \\
\hline Pharmacist: & $\begin{array}{l}\text { "It's really important to take this medication on a regular } \\
\text { basis. Did you take it as prescribed?" }\end{array}$ \\
\hline Patient: & "I know. Sometimes I forget. I don't like the side-effects." \\
\hline Pharmacist: & $\begin{array}{l}\text { "People tolerate this medication very well if they take it as } \\
\text { directed." }\end{array}$ \\
\hline Pharmacist takes a few minutes to cover the proper way to take the medication. \\
\hline Pharmacist: & $\begin{array}{l}\text { "If you keep having problems, I would advise you to talk to } \\
\text { your provider about it. Perhaps he will adjust the dose or } \\
\text { even put you on another type of medication." }\end{array}$ \\
\hline Patient: & "Yeah, okay." \\
\hline Pharmacist: & $\begin{array}{l}\text { "Okay then. Your prescription should be ready in a few } \\
\text { minutes. Any more questions?" Brief pause. "I hope you } \\
\text { take this as directed. It's really important for your health." }\end{array}$ \\
\hline
\end{tabular}

self-perception (Bem's Self-Perception Theory), ambivalence (Motivational Interviewing), stages of change (Transtheoretical Model), activation (Patient Activation Model), and planning activities (Implementation Intentions Model). ${ }^{1-8}$ In translating theory to practice, people change because their values support it, they think the change will be worth it, they think they can, they think it is important, they are ready for it, they believe that they need to take charge of their health, and they have a good plan and adequate social support. ${ }^{1-8}$ This understanding of the reasons why many people do go on to make difficult lifestyle changes is critical to shaping our strategies with patients who have trouble adhering to treatment guidelines.

\section{Why the Traditional Health Education Approach Engenders Resistance}

There is a subset of patients who do embrace the lifestyle changes and treatment plan that are necessary to manage their conditions. In these cases, education and follow-up are adequate. However, many more patients are resistant to treatment regimens. The reasons given for this resistance vary: they don't like taking medication, they don't think that their condition is severe enough to warrant behavior modification, they are too busy or stressed, they don't want to make the recommended lifestyle changes, or they don't think they can.

It becomes quite apparent that knowing what to do and putting this knowledge into action are very different issues. When a provider encounters resistance, it seems natural to provide good arguments in support of the recommendations for the specified treatment or behavior. Therefore, the provider repeats the advice and appropriate information or instructions. This evokes a natural response in the patient to present reasons why they can't, won't, aren't able to, or can't see why they should follow the advice. This effect can be seen in what's been called the "Yeah-But Dance" between the provider and the resistant patient (Table 1).

The most current behavior change research indicates that not only is this type of exchange ineffective in evoking change, but studies have shown that it predicts negative clinical outcomes. ${ }^{9,10}$ Therefore, it is likely that the worst-case scenario undermining a good clinical outcome is one in which the provider is arguing for change while the patient argues against it. Rather, a more recent perspective is that most people need more than well-intentioned advice or scare tactics to prompt them to adhere to treatment guidelines. They need an evidence-based approach that is congruent with the theories presented earlier.

It is more effective to enlist strategies that address the complex interaction of motivations, cues to action, perception of benefits and consequences, expectancies, environmental and cultural influences, self efficacy, state of readiness to change, ambivalence, and implementation intentions. Motivational interviewing is one such approach.

\section{Motivational Interviewing}

Motivational interviewing is " ... a client-centered, directive [goaloriented] method for enhancing intrinsic motivation to change by exploring and resolving ambivalence." ${ }^{5}$ The motivational interviewing approach has been incorporated across diverse populations, settings, and health topics. Its efficacy was first demonstrated in the treatment of addictions, such as illegal drugs and alcoholism. Continued research and 2 recent meta-analyses that include rigorous methodology have reinforced the evidence for the effectiveness of this client-centered approach., ${ }^{9} 10$

Motivational interviewing has since been shown to be effective in improving general health status or well-being, promoting physical activity, improving nutritional habits, encouraging medication adherence, and managing chronic conditions, such as mental illness, hypertension, hypercholesterolemia, obesity, and diabetes. ${ }^{11-31}$ In summary, motivational interviewing has been shown to be equivalent to more intensive treatment, efficacious at low doses ( $2-3$ sessions), effective as a pretreatment adjunct, effective as an approach for less-motivated or prepared people, and applicable in a wide range of situations for diverse populations. ${ }^{32}$ (See the Bibliography section at www.motivationalinterview. org for a complete listing of all published literature using the motivational interviewing approach, as well as Rollnick et al., for information on how motivational interviewing has been adapted to the health care setting. ${ }^{33}$ )

Motivational interviewing is not based on the information model; does not rely on information sharing, advice giving, or scare tactics; and is not confrontational, forceful, guilt ridden, or authoritarian. Rather, it is shaped by an understanding of what triggers change. An interaction that is consistent with motivational interviewing principles consistently outperforms traditional advice giving in the treatment of a broad range of behavioral problems and diseases. ${ }^{10}$ 
Motivational interviewing has been adapted for brief interventions and has been successfully used in the primary care setting. During a typical interaction, the proficient practitioner emphasizes the 3 underlying assumptions of motivational interviewing — collaboration, evocation, and autonomy-to establish rapport, reduce resistance, support autonomy, and elicit "change talk" (i.e., one's own reasons and arguments for change). ${ }^{33}$ The intended outcome of these motivational interviewing sessions is for clients to resolve ambivalence, move through the stages of change, and follow through on treatment guidelines, which would ostensibly result in improved clinical outcomes (Table 2).

\section{Application of Motivational Interviewing in the Primary Care or Pharmacy Setting}

The following scenarios present specific motivational interviewing techniques that the provider can use in a brief interaction in a clinic or pharmacy setting to encourage treatment adherence., ${ }^{9} 10$

\section{Expressing Empathy}

Objective: To establish rapport and avoid resistance by demonstrating your understanding of the patient's situation.

Example: "It's not easy making all of these changes."

Follow-up: "On the other hand, you did say that you know these numbers put you at risk."

\section{Rolling with Resistance}

Objective: To avoid pushing against and magnifying resistance and to allow the patient to simply explore their barriers in a nonjudgmental, supportive environment.

Example: "You really don't want to take the medication anymore. It is hard to remember to take it, and you are feeling good."

Follow-up: "I'm wondering where you see yourself in 6 months after going off the medication."

\section{Elicit-Provide-Elicit (E-P-E)}

Objective: To find out what the patient already knows, fill in the gaps or correct misconceptions, and explore how this will fit into the patient's lifestyle. This is a time-saving strategy that both validates patient knowledge and allows time to address barriers.

Example: Elicit: "Mrs. Roberts, can you tell me what you know about how this medication works and how you're supposed to take it?"... Provide (after patient answers): "That's great. You've pretty much got it nailed. I'd just like to remind you about avoiding certain foods when you take it." ... Elicit: "What do you think is the biggest barrier for you to take this regularly?"

\section{Supporting Autonomy}

Objective: To reduce resistance by assuring the patient that you know you cannot make them do anything - it is their choice. Example: "Of course, it's your choice, but as a pharmacist, I'd be concerned if you elected not to try this medication."

\section{TABLE 2 Motivational Interviewing Approach}

\begin{tabular}{|c|c|}
\hline Pharmacist: & $\begin{array}{l}\text { "I see that you haven't filled this prescription in quite a } \\
\text { while. I'm wondering how it's been going for you." }\end{array}$ \\
\hline Patient: & $\begin{array}{l}\text { "Well, I know I'm supposed to take it every day, but I don't } \\
\text { like the side-effects." }\end{array}$ \\
\hline Pharmacist: & "Tell me more about that." \\
\hline Patient: & $\begin{array}{l}\text { "Well, I've been getting nauseous sometimes and even } \\
\text { light-headed." }\end{array}$ \\
\hline Pharmacist: & $\begin{array}{l}\text { "That's not a good feeling. Have you been able to connect } \\
\text { any factors to when it happens and when it doesn't?" }\end{array}$ \\
\hline Patient: & $\begin{array}{l}\text { "That's a good question." Pause. "It may be when I skip } \\
\text { breakfast. I guess I'm supposed to eat something with it. } \\
\text { But sometimes I'm in too much of a hurry." }\end{array}$ \\
\hline Pharmacist: & $\begin{array}{l}\text { "So, when you get really busy, you take it on an empty } \\
\text { stomach and then you feel lousy." }\end{array}$ \\
\hline Patient: & $\begin{array}{l}\text { "Yeah ... exactly! But I know I should be taking it more } \\
\text { regularly." }\end{array}$ \\
\hline Pharmacist: & $\begin{array}{l}\text { "I'm wondering if you have any ideas about how you could } \\
\text { do this even when you are really busy." }\end{array}$ \\
\hline Patient: & $\begin{array}{l}\text { "Hmmm ... I guess I could just grab something easy to eat } \\
\text { in the car, like a banana or protein bar. Would that help?" }\end{array}$ \\
\hline Pharmacist: & $\begin{array}{l}\text { "I think it could. But I would encourage you to experiment } \\
\text { with different ways of taking the medication until you } \\
\text { figure out what works for you. And if your side-effects } \\
\text { persist, please do talk to your provider. So, what do you } \\
\text { think?" }\end{array}$ \\
\hline Patient: & $\begin{array}{l}\text { "I'm going to give it a try. I guess there's no reason why } \\
\text { I can't figure this out. I know I need to take these. Thanks } \\
\text { for helping me figure it out." }\end{array}$ \\
\hline Pharmacist: & $\begin{array}{l}\text { "I'm happy to brainstorm with you anytime. I really do } \\
\text { think you will be able to figure something out. This will be } \\
\text { ready in just a few minutes." }\end{array}$ \\
\hline
\end{tabular}

In this scenario, do you think the patient will take the medication as prescribed? If so, what will the patient do if there are continued side effects?

Follow-up: "Again, your doctor or I cannot make you do anything. I do think it's important that you consider all of your options and make the right choice for you at this time. If you do elect to try this medication, I can assure you that your doctor can monitor any side effects and tweak the dosage."

\section{Exploring Ambivalence}

Objective: To help the patient consider the pros and cons of change in a relaxed yet systematic manner.

Example: "So, let's talk about the pros and cons of taking this medication for your lipids."

Follow-up: "Let me see if I can summarize where you are. On the one hand, you hate the thought of going on any drug. You also don't like the copays and the hassle of filling the prescription. On the other hand, you haven't been able to do much with your diet, and work is so busy that you haven't been exercising either. You do see the importance of getting your numbers in line. Did I get it all? What do you think is the best option for you?" 


\section{Eliciting Change Talk}

Objective: To evoke from the patient his/her personal reasons, desire, ability, and need for change. This "change talk" predicts increased commitment to the lifestyle change, which in turn is correlated to good clinical outcome.

Example: "What makes it important to you to start an exercise program?" "What benefits would come from losing weight?" "Why do you want to quit smoking?"

Follow-up: "You know that exercise will help you manage your stress, lose some weight, and lower your cholesterol levels. Plus, when you did it before, you had more energy and slept better. You also want to be a good role model for the kids and be able to play sports with them."

\section{Developing a Plan of Action}

Objective: To evoke from the patient a plan that they feel is realistic and fits into their lifestyle. By having patients "own" the plan, they are more likely to follow through.

Example: "So, what's the next step for you?" "What do you think you could do (and would be willing to do) for your health right now that would make the most difference?" "What do you think is your best option?"

Follow-up: "You've outlined a great plan. You're going to try to increase the fiber in your diet and cut back on portion sizes. You're also going to try and walk more often. Lastly, you're willing to try the medication to see how that works for you. So, you're going to do this?"

These specific motivational interviewing techniques offer providers a way to encourage treatment adherence during a brief interaction with a patient in the clinic or pharmacy setting. Obviously, these various techniques should be applied in different scenarios as part of a tailored approach to increase medication adherence based on the prevailing patient and situational characteristics.

\section{Conclusions}

The most important first step toward improving your health coaching skill set is to embrace a client-centered approach. Patients can ascertain whether you are truly attempting to understand their situation and help them explore their ambivalence compared with merely trying to manipulate them into change. By respecting each patient's autonomy and resisting the urge to push against patient resistance, you have a better chance to achieve treatment compliance. Ideally, by evoking reasons, desire, ability, and need for change, you strengthen the patient's motivation to make the lifestyle change. Lastly, by allowing the patient to develop and/or own the treatment plan, the odds of reaching positive clinical outcomes are greatly improved.

\section{DISCLOSURE}

Author Susan Butterworth discloses that there was no financial relationship or financial interest relating to the topic of this activity. Butterworth was responsible for the entire study concept and design of this article. She performed all of the data collection, data interpretation, writing, and revision of this article.

\section{REFERENCES}

1. Rokeach M. The Nature of Human Values. New York: Free Press; 1973.

2. Rosenstock IM, Strecher VJ, Becker MH. Social learning theory and the health belief model. Health Educ Behav. 1988;15:175-83.

3. Bandura A. Health promotion by social cognitive means. Health Educ Behav. 2004;31:143-64.

4. Bem DJ. Self-perception theory. Available at: http://dbem.ws/SP\%20 Theory.pdf. Accessed August 30, 2007.

5. Miller W, Rollnick SR. Motivational Interviewing; Preparing People to Change. 2nd ed. New York: The Guilford Press; 2002.

6. Prochaska JO. Systems of Psychotherapy: A Transtheoretical Analysis. Homewood, IL: Dorsey Press; 1979.

7. Hibbard JH, Mahoney ER, Stock R, Tusler M. Do increases in patient activation result in improved self-management behaviors? Health Serv Res. 2007;42:1443-63.

8. Gollwitzer PM. Implementation intentions: strong effects of simple plans. Am Psychol. 1999;54:493-503.

9. Hettema J, Steele J, Miller WR. Motivational interviewing. Ann Rev Clin Psychol. 2005;1:91-111.

10. Rubak S, Sandbaek A, Lauritzen T, et al. Motivational interviewing: a systematic review and meta-analysis. Br J Gen Pract. 2005;55:305-12.

11. Butterworth S, Linden A, McClay W, et al. Effect of motivational interviewing-based health coaching on employees' physical and mental health status. J Occup Health Psychol. 2006;11:358-65.

12. Elliot DL, Goldberg L, Kuehl KS. The PHLAME (Promoting Healthy Lifestyles: Alternative Models' Effects) firefighter study: outcomes of two models of behavior change. J Occup Environ Med. 2007;49:204-13.

13. Brodie DA, Inoue A. Motivational interviewing to promote physical activity for people with chronic heart failure. J Adv Nurs. 2005;50:518-27.

14. Harland J, White M, Drinkwater C, et al. The Newcastle exercise project: a randomised controlled trial of methods to promote physical activity in primary care. BMJ. 1999;319:828-32.

15. Hudec JC. Individual counseling to promote physical activity. Dis Abst Internat Sec A: Human Soc Sci. 2000;61:931.

16. Scales R, Miller JH. Motivational techniques for improving compliance with an exercise program: skills for primary care clinicians. Curr Sports Med Rep. 2003;2:166-72.

17. Berg-Smith SM, Stevens VJ, Brown KM, et al. A brief motivational intervention to improve dietary adherence in adolescents. Health Educ Res. 1999;14:399-410.

18. Resnicow K, Jackson A, Wang T, et al. A motivational interviewing intervention to increase fruit and vegetable intake through Black churches: results of the Eat for Life trial. Am J Health Promot. 2001;91:1686-93.

19. Aliotta SL, Vlasnik JJ, Delor B. Enhancing adherence to long-term medical therapy: a new approach to assessing and treating patients. Adv Ther. 2004;21:214-31

20. Golin CE, Earp J, Tien HC, et al. A 2-arm, randomized, controlled trial of a motivational interviewing-based intervention to improve adherence to antiretroviral therapy (ART) among patients failing or initiating ART.

J Acquir Immune Defic Syndr. 2006;42:42-51. 
21. Kemp R, Kirov G, Everott B, et al. Randomised controlled trial of compliance therapy: 18-month follow-up. Br J Psychol. 1998;172:413-19.

22. Arkowitz H, Westra HA. Integrating motivational interviewing and cognitive behavioral therapy in the treatment of depression and anxiety. J Cogn Psychother. 2004;18:337-50.

23. Bellack AS, Bennett ME, Gearon JS, et al. A randomized clinical trial of a new behavioral treatment for drug abuse in people with severe and persistent mental illness. Arch Gen Psychiatry. 2006;63:426-32.

24. Ogedegbe G, Chaplin W. Motivational interviewing improves systolic blood pressure in hypertensive African Americans. Am J Hypertens. 2005; 18:A212.

25. Woollard J, Beilin L, Lord T, et al. A controlled trial of nurse counseling on lifestyle change for hypertensives treated in general practice: preliminary results. Clin Exp Pharmacol Physiol. 1995;22:466-68.

26. Mhurchu CN, Margetts BM, Speller V. Randomized clinical trial comparing the effectiveness of two dietary interventions for patients with hyperlipidaemia. Clin Sci. 1998;95:479-87.

27. DiLillo V, Siegfried NJ, West DS. Incorporating motivational interviewing into behavioral obesity treatment. Cogn Behav Pract. 2003;10:120-30.
28. Smith DE, Heckemeyer CM, Kratt PP, et al. Motivational interviewing to improve adherence to a behavioral weight-control program for older obese women with NIDDM. A pilot study. Diabetes Care. 1997;20:52-54.

29. West DS, DiLillo V, Bursac Z, et al. Motivational interviewing improves weight loss in women with type 2 diabetes. Diabetes Care. 2007;30:1081-87.

30. Channon S, Smith VJ, Gregory JW. A pilot study of motivational interviewing in adolescents with diabetes. Arch Dis Child. 2003;88:680-83.

31. Pill R, Stott NC, Rollnick SR, et al. A randomized controlled trial of an intervention designed to improve the care given in general practice to type Il diabetic patients: patient outcomes and professional ability to change behaviour. Fam Pract. 1998;15:229-35.

32. Burke BL, Arkowitz H, Menchola M. The efficacy of motivational interviewing: a meta-analysis of controlled clinical trials. J Consult Clin Psychol. 2003;71;843-61.

33. Rollnick S, Miller WR, Butler CC. Motivational Interviewing in Health Care: Helping Patients Change Behavior. New York: Guilford Press; November 2007. 